\title{
Effect of glucocorticoids on adiponectin: a study in healthy subjects and in Cushing's syndrome
}

Francesco Fallo, Alessando Scarda, Nicoletta Sonino ${ }^{1}$, Agostino Paoletta ${ }^{2}$, Marco Boscaro ${ }^{3}$, Claudio Pagano, Giovanni Federspil and Roberto Vettor

Department of Medical and Surgical Sciences and ${ }^{1}$ Department of Statistical Sciences, University of Padova, Italy, ${ }^{2}$ Division of Medicine, City Hospital, Cittadella, Italy and ${ }^{3}$ Endocrinology Unit, University of Ancona, Italy

(Correspondence should be addressed to F Fallo, Department of Medical and Surgical Sciences, University of Padova, Via Ospedale 105, 35128 Padova, Italy; Email: francesco.fallo@unipd.it)

\begin{abstract}
Objective: Glucocorticoids were found to inhibit adiponectin gene expression and secretion both in vitro and in animal models. We evaluated first the acute effect of i.v. glucocorticoids on adiponectin in normal subjects and secondly plasma adiponectin levels in a series of patients with Cushing's syndrome compared with controls.

Design and methods: Hydrocortisone $(25 \mathrm{mg})$ was administered i.v. to five healthy volunteers, with blood samples taken at $-15,0,30,60,120$ and $180 \mathrm{~min}$. Twenty-one patients with Cushing's syndrome were divided in two groups: one with 11 obese and the other with 10 non-obese Cushing's patients. Each group was compared with controls that were matched for sex, age, body mass index, waist circumference, glucose, insulin, lipid levels and blood pressure.

Results: In normal subjects, hydrocortisone produced a decrease in adiponectin at 30 and $60 \mathrm{~min}$, compared with placebo $(P<0.05)$. Adiponectin was lower in non-obese Cushing's patients than in non-obese controls $(P<0.004)$. In contrast, there was no difference in adiponectin levels in obese Cushing's patients and in obese controls. Adiponectin was inversely correlated $(P<0.05)$ with homeostasis model assessment index in both obese and non-obese Cushing's patients; in nonobese Cushing's patients only, adiponectin was inversely correlated with urinary cortisol $(P<0.05)$

Conclusions: Glucocorticoids inhibit adiponectin in man, as shown by both exogenous administration to healthy subjects and endogenous cortisol hyperproduction. Similar levels of adiponectin in obese Cushing's patients and their obese controls indicate that obesity per se may act as a predominant factor in masking the relationship between adiponectin and cortisol.
\end{abstract}

European Journal of Endocrinology 150 339-344

\section{Introduction}

Adiponectin (AdipoQ, Acrp30) is the protein product of the apM1 gene, which is expressed exclusively in adipose tissue (1). Plasma adiponectin levels are reduced in clinical conditions associated with insulin resistance, including obesity, type 2 diabetes, hypertension and lypodistrophies (2). Cortisol excess in man is characterized by abdominal obesity, hypertension, glucose intolerance or diabetes and dyslipidemia. All these features share a state of insulin resistance (3), and contribute to high cardiovascular risk typical of this condition (4-6). Scarce data are available on the possible regulation of adiponectin by glucocorticoids. Dexamethasone has been shown to reduce adiponectin gene expression in murine 3T3-L1 adipocytes (7), and glucocorticoids negatively regulate adiponectin mRNA in human visceral adipose tissue (8). Adiponectin expression in white adipose tissue is stimulated by adrenalectomy in $o b / o b$ mice (9). It is also known that the promoter region of the gene encoding adiponectin contains consensus sequences for glucocorticoid-receptor binding (10).

The aim of the study was to evaluate: (1) the acute effect of glucocorticoid i.v. administration on adiponectin in normal subjects; and (2) the plasma levels of adiponectin in a series of patients with Cushing's syndrome, and their association with clinical, biochemical and endocrine-metabolic parameters, in comparison with a control population. 


\section{Subjects and methods}

\section{Protocol 1. Acute effect of glucocorticoids on adiponectin}

To test adiponectin response to glucocorticoids, hydrocortisone (Solucortef, Pharmacia-Upjohn), was administered to five healthy volunteers (mean age, $30 \pm 6$ years; range, 22-37 years; three women and two men) in a single-blind, placebo-controlled, random order. Tests were performed in the morning at $0800 \mathrm{~h}$, with subjects maintaining a supine position after overnight fasting. Hydrocortisone $(25 \mathrm{mg})$ was administered as an i.v. bolus in $30 \mathrm{~s}$ through a cannula placed in the forearm $1 \mathrm{~h}$ before testing. Blood samples for plasma adiponectin, adrenocorticotropic hormone (ACTH) and cortisol were drawn from the opposite forearm at $-15,0,30,60,120$ and $180 \mathrm{~min}$. As a control, $2-4$ days earlier, saline rather than hydrocortisone was injected in the same subjects using the same protocol. The baseline value was the mean between -15 and 0 min values. Decrease of ACTH levels at the same time points was assumed as an index of hydrocortisone effect (11). No side-effects were observed, and none of the subjects was excluded from the protocol.

\section{Protocol 2. Cushing's syndrome}

The study involved 21 consecutive patients (mean age, $33 \pm 16$ years; range, $16-58$ years, 14 women and 7 men) with newly diagnosed Cushing's syndrome, admitted to our Institutions during the last 3 years. The diagnosis of Cushing's syndrome was based on standard criteria (6). Among the patients with Cushing's syndrome, 15 had a pituitary-dependent Cushing's disease, 4 had an adrenal adenoma, 1 had an adrenal carcinoma, and 1 had an ACTH ectopic production. These 21 patients were divided in two groups. The first group included 11 obese Cushing's patients, i.e. patients having a body mass index (BMI) $>30 \mathrm{~kg} / \mathrm{m}^{2}$ and waist circumference $>88 \mathrm{~cm}$ for women and $>102 \mathrm{~cm}$ for men; the second group included 10 non-obese Cushing's patients. Each group of patients was compared with control cases that were matched for sex, age, BMI, waist circumference, glucose and lipid levels, and blood pressure. Controls were selected from diabetic, hyperlipidemic, essential hypertensive patients, and patients with post-pubertal obesity seen at our outpatient clinic, and from a general population under evaluation for cardiovascular risk stratification.

In the Cushing's patients and in controls, diabetes mellitus was diagnosed when, in the absence of treatment, fasting blood glucose was higher than $7.0 \mathrm{mmol} / \mathrm{l}$ in two consecutive determinations (12). Hyperlipidemia was defined as fasting total serum cholesterol $>5.7 \mathrm{mmol} / \mathrm{l}$ and/or serum triglycerides $>1.8 \mathrm{mmol} / \mathrm{l}$. Hypertension was defined as a systolic blood pressure of $140 \mathrm{mmHg}$ or more and/or diastolic blood pressure of $90 \mathrm{mmHg}$ or more, based on the average of two or more readings taken in sitting position at different days before investigation. The waist circumference measurement, taken as a reference measure of abdominal obesity, was made at minimal inspiration to the nearest $0.1 \mathrm{~cm}$, midway between the last rib and the iliac crest. Cut-off points for obesity and waist circumference were taken according to the National Institutes of Health guidelines (13). Insulin sensitivity was calculated according to the formula of the homeostasis model assessment (HOMA) method: insulin resistance $=$ fasting plasma insulin $(\mu \mathrm{U} / \mathrm{ml}) \times$ fasting plasma glucose $(\mathrm{mmol} / \mathrm{l}) / 22.5$ (14). The index is highly correlated with the insulin resistance index assessed by the euglycemic-hyperinsulinemic clamp; this is the gold standard of insulin resistance (15), and is widely adopted in clinical studies.

The study had approval from the local Ethics Committee and all subjects gave their informed consent.

\section{Laboratory studies}

Blood samples for biochemical and endocrine-metabolic profile were obtained after overnight fasting at $0800 \mathrm{~h}$. Plasma ACTH was measured by a two-site immunoradiometric assay from Nichols Institute (San Juan Capistrano, CA, USA). Normal values at $0800 \mathrm{~h}$ were up to $22 \mathrm{pmol} / \mathrm{l}$. Plasma and urinary cortisol were measured by RIA kit from Diagnostic Products Corp. (Los Angeles, CA, USA). Normal ranges were: plasma cortisol at $0800 \mathrm{~h}, 138-550 \mathrm{nmol} / \mathrm{l}$; urinary cortisol, $55-331 \mathrm{nmol} / 24 \mathrm{~h}$. Serum insulin was measured using a RIA kit from Behring (Scoppito, Italy); normal range, $\quad 43-172 \mathrm{pmol} / \mathrm{l}$. Plasma adiponectin was measured by a specific RIA obtained from Linco Research, Inc. (St Charles, MO, USA), with minor modifications, as previously described (16). Recombinant human adiponectin was used as standard, and a multispecies adiponectin rabbit antiserum was used. The assay buffer contained $10.0 \mathrm{mmol}$ phosphate buffer, $\mathrm{pH} 7.6$, sodium azide $(0.09 \%)$ and BSA $(0.15 \%)$. For all hormone measurements, intra- and inter-assay coefficients of variation were less than $10 \%$. All other biochemical variables were assayed in the same laboratory using standard methods.

\section{Statistical analysis}

All values are expressed as means \pm S.D. The analysis of adiponectin response at subsequent time points, with respect to the baseline level, was made by paired Student's $t$-test. The adiponectin response to hydrocortisone vs placebo was compared by two-way ANOVA with repeated measures, using treatment as the grouping factor. Statistical significance between the group of Cushing's patients and matched controls was assessed by Student's unpaired $t$-test, with Bonferroni correction for multiple comparisons. $\chi^{2}$ statistics were used to 
assess differences between categorical variables. Relationships were assessed by using Pearson's correlation coefficient and linear regression analysis. Statistical significance was accepted as $P<0.05$. For the $t$-test corrected for multiple comparisons, $P<0.0041$ (Bonferroni adjustment) was used as significance level.

\section{Results}

\section{Protocol 1}

Figure 1 shows the response of adiponectin to acute hydrocortisone in comparison with placebo injection. Hydrocortisone (25 mg as an i.v. bolus) produced a decrease in circulating adiponectin levels at 30 and $60 \mathrm{~min}$, from $29.3 \pm 3.7$ baseline to $24.2 \pm 5.1$ and to $22.6 \pm 2.1 \mu \mathrm{g} / \mathrm{ml}$ respectively $(P<0.01)$, which was significant in comparison with placebo $(P<0.05)$. Adiponectin decrease was followed by an increase thereafter at 120 and $180 \mathrm{~min}$, with levels not differing from those found after placebo administration. The lowest levels of adiponectin occurred in association with the maximal rise of plasma cortisol after hydrocortisone i.v. bolus.
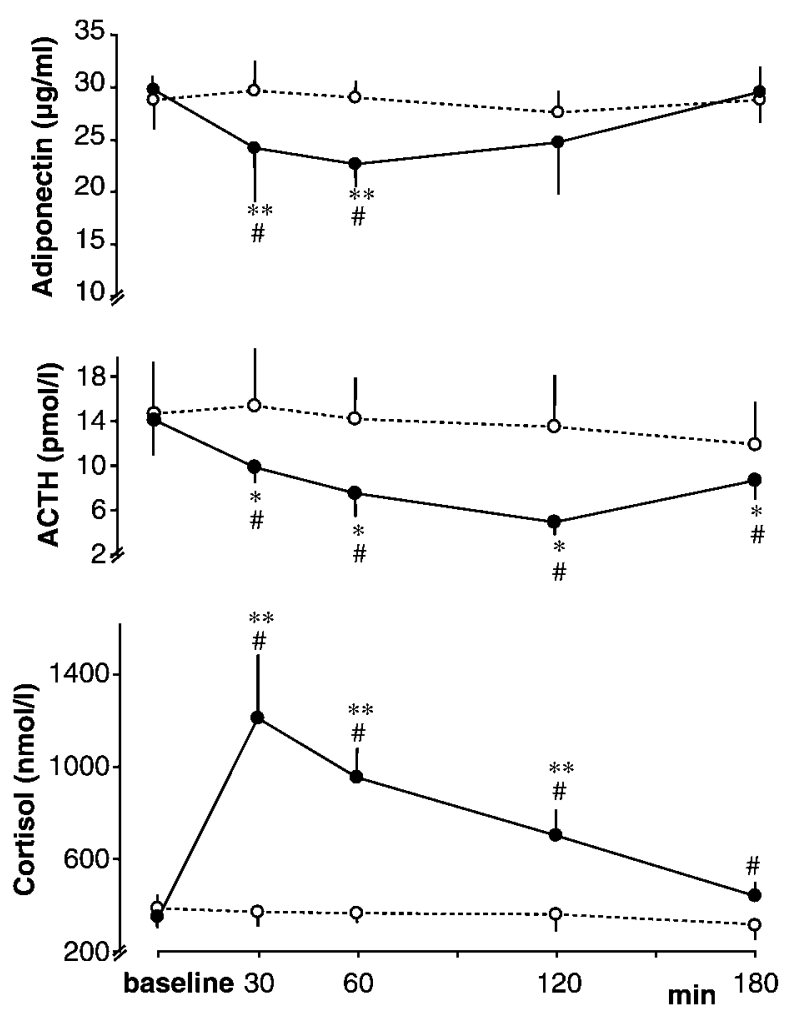

Figure 1 Plasma adiponectin, ACTH and cortisol response to hydrocortisone i.v. bolus (•) and to placebo (०) in normal subjects $(n=5) .{ }^{*} P<0.01$ and ${ }^{*} P<0.05$ compared with baseline; ${ }^{\#} P<0.05$ compared with placebo.

\section{Protocol 2}

Clinical and endocrine-metabolic parameters of the two groups of patients with Cushing's syndrome and matched controls are reported in Table 1 . The two groups of patients with Cushing's syndrome were similar for age and sex and were not statistical different in terms of blood pressure, glucose, total cholesterol, triglyceride, and urinary cortisol levels. Serum insulin levels and HOMA index were lower in non-obese controls than in all other groups of subjects. The proportion of diabetic, hyperlipidemic and hypertensive patients was the same in obese Cushing's patients and obese controls $(n=2 / 11, n=5 / 11, n=5 / 11$ respectively), as well as in non-obese Cushing's patients and non-obese controls $(n=2 / 10, n=4 / 10, n=4 / 10$ respectively). Adiponectin was lower in non-obese Cushing's patients than in non-obese controls $(20.9 \pm 7.3$ vs $30.9 \pm 4.9 \mu \mathrm{g} / \mathrm{ml}, P<0.004)$. In contrast, adiponectin levels were not different in obese Cushing's patients and in obese controls $(22.1 \pm 6.9$ vs $20.1 \pm 2.7 \mu \mathrm{g} / \mathrm{ml}, P=\mathrm{NS}$ ). Individual data are reported for the four groups of subjects (Fig. 2). Adiponectin was inversely correlated with the HOMA index in both obese and non-obese Cushing's patients $(P<0.05)$. A significant inverse correlation between adiponectin levels and urinary cortisol was found only in the group of non-obese Cushing's patients $(P<0.05)$ (Fig. 3).

\section{Discussion}

Our results, showing an acute decrease of adiponectin of about $25 \%$, in response to i.v. exogenous glucocorticoid administration in healthy subjects, are in favour of a direct inhibitory effect of cortisol on adiponectin. The adiponectin decrease was transient, probably due to the fact that hydrocortisone was administered as a bolus, and not as an infusion. To our knowledge, there is no information on the adiponectin half-life in vivo in humans; however, since hydrocortisone administered intravenously has been shown to have a half-life of $1.7 \mathrm{~h}$ (17), its lowering effect on adiponectin should last 90-120 min in our normal subjects. Whether adiponectin inhibition was due to reduced release from adipose tissue, or to decreased synthesis, should be clarified by gene expression studies in adipocytes. A model of endogenous cortisol excess, such as Cushing's syndrome, also seems to confirm an inverse relationship between glucocorticoids and adiponectin. In fact, non-obese patients with Cushing's syndrome had lower adiponectin than control cases. The HOMA index was abnormally high in the group of non-obese Cushing's patients, confirming a decreased insulin sensitivity in this disease, which could be ascribed to a post-insulin receptor defect (3). The HOMA index was inversely correlated with adiponectin in both obese and non-obese Cushing's patients. Accordingly, 
Table 1 Details of patients and controls included in the study.

\begin{tabular}{|c|c|c|c|c|}
\hline & $\begin{array}{l}\text { Obese Cushing's } \\
(n=11)\end{array}$ & $\begin{array}{l}\text { Obese controls } \\
\qquad(n=11)\end{array}$ & $\begin{array}{l}\text { Non-obese Cushing's } \\
\qquad(n=10)\end{array}$ & $\begin{array}{c}\text { Non-obese controls } \\
\qquad(n=10)\end{array}$ \\
\hline Age (years) & $40 \pm 13$ & $38 \pm 9$ & $26 \pm 10$ & $30 \pm 11$ \\
\hline $\operatorname{Sex}(M / F)$ & $4 / 7$ & $4 / 7$ & $3 / 7$ & $3 / 7$ \\
\hline $\mathrm{BMI}\left(\mathrm{kg} / \mathrm{m}^{2}\right)$ & $33.8 \pm 4.2^{\mathrm{a}}$ & $34.3 \pm 3.6^{\mathrm{a}}$ & $25.8 \pm 2.3$ & $26.2 \pm 2.5$ \\
\hline Waist circumference (cm) & $106.3 \pm 3.7^{\mathrm{a}}$ & $107.4 \pm 14.6^{\mathrm{a}}$ & $88.2 \pm 8.8$ & $87.1 \pm 7.4$ \\
\hline Systolic BP (mmHg) & $159.0 \pm 22.6$ & $162.2 \pm 22.2$ & $153.1 \pm 18.2$ & $155.2 \pm 19.1$ \\
\hline Diastolic BP $(\mathrm{mmHg})$ & $95.5 \pm 5.9$ & $94.3 \pm 10.4$ & $91.9 \pm 14.9$ & $92.1 \pm 17$ \\
\hline Fasting glucose (mmol/l) & $6.0 \pm 1$ & $5.9 \pm 1.4$ & $5.6 \pm 0.8$ & $4.9 \pm 1.4$ \\
\hline Fasting insulin (pmol/l) & $135.8 \pm 30.4$ & $123 \pm 42.3$ & $105.4 \pm 27.2$ & $66.4 \pm 19.2^{b}$ \\
\hline HOMA index & $5.1 \pm 1.6$ & $4.7 \pm 2.2$ & $3.7 \pm 1.5$ & $2.1 \pm 1.1^{b}$ \\
\hline Total cholesterol (mmol/l) & $6.0 \pm 0.9$ & $5.8 \pm 0.9$ & $5.7 \pm 1.0$ & $5.9 \pm 1.2$ \\
\hline Triglycerides $(\mathrm{mmol} / \mathrm{l})$ & $1.7 \pm 0.7$ & $1.6 \pm 0.7$ & $1.4 \pm 0.8$ & $1.3 \pm 0.6$ \\
\hline Adiponectin $(\mu \mathrm{g} / \mathrm{ml})$ & $22.1 \pm 6.9$ & $20.1 \pm 2.7$ & $20.9 \pm 7.3$ & $30.9 \pm 4.9^{c}$ \\
\hline Urinary cortisol (nmol/24h) & $1451 \pm 972$ & $281 \pm 74^{d}$ & $839 \pm 666$ & $238 \pm 66^{d}$ \\
\hline
\end{tabular}

$\mathrm{BMI}$, body mass index; BP, blood pressure.

a $P<0.0001$ vs non-obese Cushing's patients and non-obese controls.

${ }^{\mathrm{b}} P<0.001$ vs obese Cushing's patients, obese controls and non-obese Cushing's patients.

${ }^{c} P<0.004$ vs non-obese and obese Cushing's patients, and $P<0.001$ vs obese controls.

${ }^{\mathrm{d}} P<0.001$ vs obese Cushing's patients and non-obese Cushing's patients.

plasma adiponectin concentrations were found to correlate inversely with the severity of insulin resistance (18), and to increase during treatment with thioglitazones (19), in human studies. On the basis of our data, both adiponectin decrease after hydrocortisone in normal subjects, and lower adiponectin in nonobese Cushing's patients compared with controls, suggest that hypoadiponectinemia is an important factor in glucocorticoid-induced insulin resistance of non-obese patients with Cushing's syndrome. Due to the very small intragroup size of the male vs female samples, no conclusion could be drawn on a possible sexual dimorphism in adiponectin levels, as previously observed (20).

Insulin resistance is considered to have a key role in the metabolic syndrome or syndrome $\mathrm{X}$; this includes obesity, hypertension, glucose intolerance

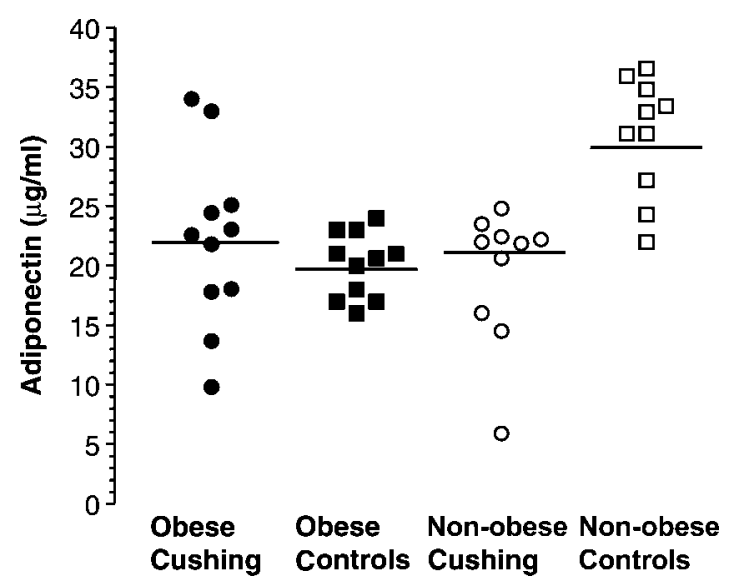

Figure 2 Individual data of plasma adiponectin in obese Cushing's patients $(\bullet)$, obese controls $(\boldsymbol{\square})$, non-obese Cushing's patients $(\bigcirc)$ and non-obese controls $(\square)$. The horizontal lines for each group represent mean values. and hyperlipidemia, and is associated with increased cardiovascular risk $(21,22)$. Cortisol may have a pathogenetic role in this syndrome. In fact, cortisol counteracts the action of insulin at multiple sites (23-25), and increases hepatic gluconeogenetic efficiency (26). It promotes abdominal fat distribution (24), enhances sympathetic nervous system activity (25), and has complex effects on vascular tone promoting endothelial dysfunction (27), hypercoagulability (28) and hypertension (29). In our study, a
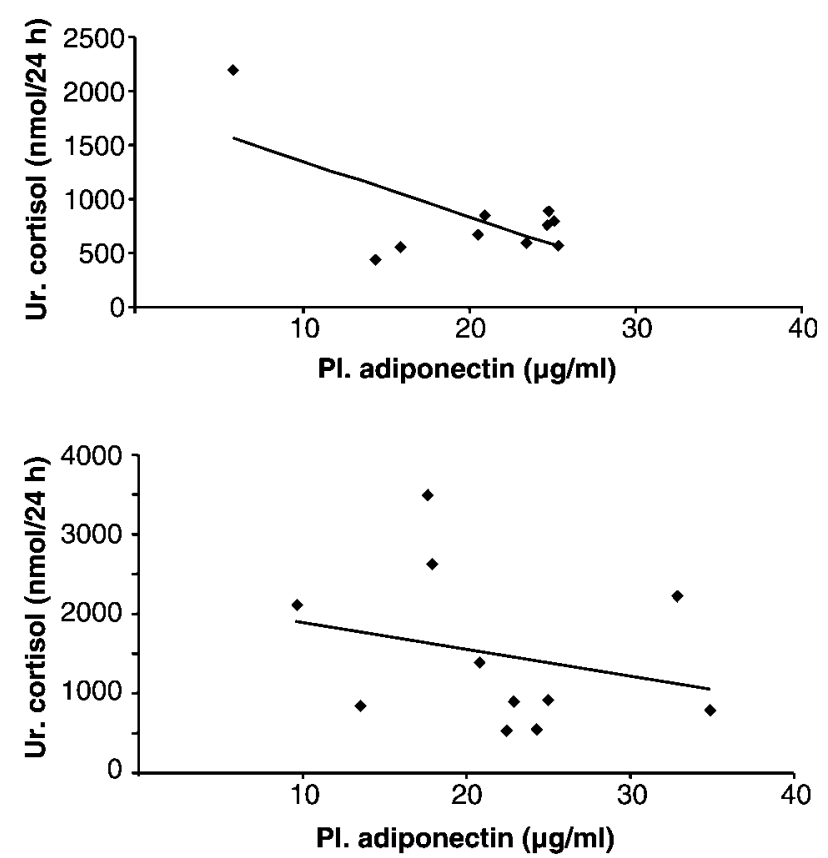

Figure 3 Relationship between urinary cortisol and plasma adiponectin in non-obese Cushing's patients $(r=-0.64, P<0.05)$, upper panel, and in obese Cushing's patients $(r=-0.29$, $P=$ NS), lower panel. 
similar proportion of cases with non-insulin dependent diabetes, dyslipidemia and hypertension in the groups of obese and non-obese Cushing's patients, should exclude the possibility of an interference of these conditions on adiponectin results. Adiponectin was decreased in non-obese Cushing's patients in comparison with non-obese controls, and an inverse correlation between urinary cortisol and adiponectin was found in non-obese Cushing's patients but not in obese Cushing's patients. Since adiponectin levels were similar in obese Cushing's patients and their obese controls, this may simply indicate that obesity per se acts as a predominant factor masking the relationship between adiponectin and cortisol. The changes in adiponectin after glucocorticoids or in Cushing's syndrome seem to be inverse to those of leptin, another adipocyte-produced cytokine. Leptin is, in fact, known to be markedly increased after glucocorticoid administration and in Cushing's syndrome (30). At variance with our findings on adiponectin, a recent paper has suggested that chronic hypercortisolemia in Cushing's syndrome does not directly affect serum leptin concentrations but acts via the associated hyperinsulinemia and/or impaired insulin sensitivity (31).

A limitation of our study was the lack of an accurate measurement of body fat distribution in our Cushing's patients. An abnormal increase of visceral fat percentage and visceral/subcutaneous fat ratio has been demonstrated by computed tomography (CT) scan in Cushing's syndrome (32). Although waist circumference was similar in our patients with Cushing's syndrome and their controls, this parameter does not allow clarification of whether reduced adiponectin levels were specifically associated with the abdominal repartition of fat, as is typical of this disease.

In conclusion, glucocorticoids inhibit adiponectin in man as shown by both acute exogenous administration to healthy subjects and chronic endogenous hypercortisolism. Since adiponectin has been suggested to be a link between insulin resistance and vascular disease in the metabolic syndrome (33), the decrease of adiponectin, in association with other independent mechanisms, may contribute to the increased cardiovascular risk in non-obese Cushing's syndrome.

\section{Acknowledgements}

The excellent technical assistance of Marilena Tormene and Sonia Leandri is greatly appreciated. This study was supported by grant 2001065883-003 from MIUR, Roma, Italy. The authors have no conflict of interest to declare.

\section{References}

1 Maeda K, Okubo K, Shimomura I, Funahashi T, Matsuzawa Y \& Matsubara K. cDNA cloning and expression of a novel adipose specific collagen-like factor, apM1 (Adipose Most abundant Gene transcript 1). Biochemical and Biophysical Research Communications $1996221286-289$.

2 Diez JJ \& Iglesias P. The role of the novel adipocyte-derived hormone adiponectin in human disease. European Journal of Endocrinology 2003148 293-300.

3 Andrews RC \& Walker BR. Glucocorticoids and insulin resistance: old hormones, new targets. Clinical Science 199996 513-523.

4 Colao A, Pivonello R, Spiezia S, Faggiano A, Ferone D, Filippella M et al. Persistence of increased cardiovascular risk in patients with Cushing's disease after five years of successful cure. Journal of Clinical Endocrinology and Metabolism $1999842664-2672$.

5 Lindholm J, Juul S, Jorgensen JOL, Astrup J, Bjerre P, Feldt-Rasmussen U et al. Incidence and late prognosis of Cushing's syndrome. A population-based study. Journal of Clinical Endocrinology and Metabolism 200186 117-123.

6 Boscaro M, Barzon L, Fallo F \& Sonino N. Cushing's syndrome. Lancet 2001357 783-791.

7 Fasshauer M, Klein J, Neumann S, Eszlinger M \& Paschke R. Hormonal regulation of adiponectin gene expression in 3T3-L1 adipocytes. Biochemical and Biophysical Research Communications $20022901084-1089$.

8 Halleux CM, Takahashi M, Delporte ML, Detry R, Funahashi T, Matsuzawa Y et al. Secretion of adiponectin and regulation of apM1 gene expression in human adipose visceral tissue. Biochemical and Biophysical Research Communications $20012 \mathbf{2 8 8}$ 1102-1107.

9 Makimura H, Mizuno TM, Bergen H \& Mobbs CV. Adiponectin is stimulated by adrenalectomy in ob/ob mice and is highly correlated with resistin mRNA. American Journal of Physiology-Endocrinology and Metabolism 2002283 E1266-E1271.

10 Comuzzie AG, Funahashi T, Sonnenberg G, Martin LJ, Jacob HJ, Kwitek Black AE et al. The genetic basis of plasma variation in adiponectin, a global phenotype for obesity and the metabolic syndrome. Journal of Clinical Endocrinology and Metabolism 2001 $864321-4325$.

11 Boscaro M, Paoletta A, Scarpa E, Barzon L, Fusaro P, Fallo F et al. Age-related changes in glucocorticoid fast feedback inhibition of adrenocorticotropin in man. Journal of Clinical Endocrinology and Metabolism 199883 1380-1383.

12 Report of the Expert Committee on the Diagnosis and Classification of Diabetes Mellitus. Diabetes Care 19981 (Suppl 1) S5-S19.

13 National Institutes of Health, National Heart, Lung and Blood Institute. Clinical guidelines on the identification, evaluation, and treatment of overweight and obesity in adults: the evidence report. Obesity Research 19986 (Suppl 2) S51-S210.

14 Matthews DR, Hosker JP, Rudenski AS, Naylor BA, Treacher DF \& Turner RC. Homeostasis model assessment: insulin resistance and $\beta$-cell function from fasting plasma glucose and insulin concentration in man. Diabetologia $1985 \mathbf{2 8} 412-419$.

15 Emoto M, Nishizawa Y, Maekava K, Hiura Y, Kanda H, Kawagishi $\mathrm{T}$ et al. Homeostasis model of assessment as a clinical index of insulin resistance in type 2 diabetic patients treated with sulfonylureas. Diabetes Care 199922 818-822.

16 Pannacciulli N, Vettor R, Milan G, Granzotto M, Catucci A, Federspil G et al. Anorexia nervosa is characterized by increased adiponectin plasma levels and reduced nonoxidative glucose metabolism. Journal of Clinical Endocrinology and Metabolism 200388 1748-1752.

17 Derendorf H, Mollmann H, Barth J, Mollmann C, Tunn S \& Krieh M. Pharmacokinetics and oral bioavailability of hydrocortisone. Journal of Clinical Pharmacology 199131 473-476.

18 Weyer C, Funahashi T, Tanaka S, Hotta K, Matsuzawa Y, Pratley RE et al. Hypoadiponectinemia in obesity and type 2 diabetes: close association with insulin resistance and hyperinsulinemia. Journal of Clinical Endocrinology and Metabolism 200186 $1930-1935$.

19 Yu JG, Javorski S, Hevener AL, Kruszynska YT, Norman RA, Sinha $\mathrm{M}$ et al. The effect of thiazolidinediones on plasma adiponectin levels in normal, obese and type 2 diabetic subjects. Diabetes $2002512968-2974$. 
20 Kern PA, Gregorio G, Lu T, Rassouli N \& Ranganathan G. Adiponectin expression from human adipose tissue. Relation to obesity, insulin resistance, and tumor necrosis factor- $\alpha$ expression. Diabetes 200352 1779-1785.

21 Reaven GM. Banting Lecture 1988: role of insulin resistance in human disease. Diabetes 198837 1595-1607.

22 DeFronzo RA \& Ferrannini E. Insulin resistance: a multifaceted syndrome responsible for NIDDM, obesity, hypertension, dyslipidemia, and atherosclerotic cardiovascular disease. Diabetes Care 199114 173-194.

23 Holmang A \& Biorntop P. The effects of cortisol on insulin sensitivity in muscle. Acta Physiologica Scandinavica $1992 \mathbf{1 4 4}$ 425-431.

24 Dinneen S, Alzaid A, Miles J \& Rizza R. Metabolic effects of the nocturnal rise in cortisol in carbohydrate metabolism in normal subjects. Journal of Clinical Investigation 199392 2283-2290.

25 Bjorntorp P \& Rosmond R. Obesity and cortisol. Nutrition 2000 $16924-936$.

26 Khani S \& Tayek JA. Cortisol increases gluconeogenesis in humans: its role in the metabolic syndrome. Clinical Science $2001101739-747$.

27 Ullian ME. The role of corticosteroids in the regulation of vascular tone. Cardiovascular Research $1999 \mathbf{4 1}$ 55-64.

28 Boscaro M, Sonino N, Scarda A, Barzon L, Fallo F, Sartori MT et al. Anticoagulant prophylaxis markedly reduced thromboembolic complications in Cushing's syndrome. Journal of Clinical Endocrinology and Metabolism $2002873662-3666$.

29 Whitworth JA, Mangos GJ \& Kelly JJ. Cushing, cortisol and cardiovascular disease. Hypertension $200036912-916$.

30 Masuzaki H, Ogawa Y, Hosoda K, Miyawaki T, Hanaoka I, Hiraoka J et al. Glucorticoid regulation of leptin synthesis and secretion in humans: elevated plasma leptin levels in Cushing's syndrome. Journal of Clinical Endocrinology and Metabolism 1997 $822542-2547$.

31 Widiaja A, Schurmeyer TH, Von zur Muhlen A \& Brabant G. Determinants of serum leptin levels in Cushing's syndrome. Journal of Clinical Endocrinology and Metabolism 199883 600-603.

32 Rockall AG, Sohaib SA, Evans D, Kaltsas G, Isidori AM, Monson JP et al. CT assessment of fat distribution in male and female patients with Cushing's syndrome. European Journal of Endocrinology 2003 $149561-567$.

33 Ukkola O \& Santaniemi M. Adiponectin: a link between excess adiposity and associated comorbidities? Journal of Molecular Medicine $200280696-702$.

Received 10 September 2003

Accepted 21 November 2003 